\title{
LECCIONES DE PSICOLOGÍA: NOTAS SOBRE LA LECTURA NIETZSCHEANA DE HUMILLADOS Y OFENDIDOS DE DOSTOIEVSKI ${ }^{1}$ \\ Psychology lessons: notes on the Nietzschean reading of Dostoyevski's The Insulted and Injured
}

\author{
Joan B. Llinares
}

Universitat de València

RESUMEN: Este texto, primera parte de un extenso estudio sobre la lectura nietzscheana de Humillados y ofendidos de F. Dostoievski, arranca con una reflexión sobre la actualidad del análisis de las relaciones entre ambos escritores como un reto que sigue abierto en la Nietzsche-Forschung. Desde los documentos que testimonian dicha lectura y sus efectos («mit dem grössten Respekt vor dem Künstler Dostoiewsky»), se evidencia que hay que clarificar la concepción del artista que aquí se manifiesta. Las cartas de Nietzsche demuestran por otra parte que el filósofo valoró al escritor ruso sobre todo en cuanto psicólogo, segundo tema a explicitar. Los textos de E. M. de la Vogüé sobre Dostoievski, de muy probable lectura por parte de Nietzsche, destacan tres aspectos que afianzan nuestro análisis: el arte trágico del novelista, su peculiar talante filosófico y los rasgos de Humiliés et offensés que convierten este libro en un antecesor de El idiota y, en consecuencia, en una de las fuentes de El Anticristo.

Palabras clave: arte - artista - psicología - arte trágico - anticristo

ABSTRACT: This text, part of an extensive study on the Nietzschean reading of The Insulted and Injured by Dostoevsky, begins with a reflection on the currency of the analysis of

1. Este trabajo es el primero de una investigación que continuará en otras publicaciones con los siguientes puntos:

1. La versión de J. M. Mejía: la forma como contenido, el contenido como forma, el escritor Iván P. como artista. Escritura, fuerza y locura. La ebriedad del artista: Dostoievski como liberación.

2. Paralelismos biográficos entre el personaje de Iván P. y Nietzsche.

3. ¿Qué significa escribir? Escritura y verdad, escritura e invención. La experiencia del «terror místico». La novela como anatomía de la gran ciudad.

4. Contra el humanitarismo sentimental, el romanticismo, la filantropía y el idealismo: críticas a los seguidores de Schiller, los corazones débiles, las almas bellas, los individuos sin carácter ni voluntad, utópicos ingenuos, charlatanes sin acción, farsantes a desenmascarar.

5. Fisiología del amor: una pasión fatal, un ejercicio de poder y dominación, una vivencia cruel y torturante (la rivalidad y los celos, la amistad imposible).

6. Análisis del egoísmo: críticas al masoquismo (el «egoísmo del sufrimiento») y al sadismo. El egoísmo como virtud: crítica a la moral como confort. El debate con de Laclos y de Sade, M. Stirner y N. Chernischevski.

7. Contra el resentimiento y el arrepentimiento: análisis de la culpa y la mala conciencia. La necesidad de la «descarga» psíquica. La tragedia de la liberación femenina en un mundo patriarcal.

8. Ausencias de una traducción incompleta: ¿qué son los alemanes?; la música y los sentimientos; la alusión al «gato negro» (para una antropología de la «perversidad»). 
the relations between both authors, as a challenge that remains open in the 'NietzscheForschung'. From the documents we testify that reading and its effects («mit dem grössten Respekt vor dem Künstler Dostoiewsky») there is evidence to clarify the artist's conception shown here. Nietzsche's letters show, moreover, that the philosopher praised the Russian writer especially as psychologist, and this is the second issue we want to explain. The texts on Dostoevsky by E. M. Vogüé, most likely read by Nietzsche, highlight three aspects which consolidate our analysis: the tragic art of the novelist, the peculiar philosophical mood traits of Humiliés et offensés, that make this book a predecessor of The Idiot and, consequently, a source of The Antichrist.

Keywords: Artist - Psychology - Tragic Art

\section{SOBRE LA «ACTUALIDAD Y/O INACTUALIDAD» DEL ESTUDIO DE LAS RELACIONES ENTRE NIETZSCHE Y DOSTOIEVSKI: UN RETO PARA LA NIETZSCHE-FORSCHUNG}

Comenzaremos con la cuestión que nos convoca: en Nietzsche, «intempestivo» no equivale a «inactual» o «anacrónico», menos aún a «pasado de moda» $\mathrm{o}$ «anticuado", significa algo más hondo y subversivo; «intempestividad» - o «extemporaneidad»— quiere decir «ir contra la corriente», «oponerse al tiempo presente», que es mayoritariamente historicista (y cientificista, nacionalista, filisteo de la formación, etc.) a riesgo de quedarse en minoría y dufrir dolorosa soledad, y hacerlo «en favor de un tiempo futuro", gracias en parte a conocer a fondo una época del pasado de genuina gran cultura, como la Grecia trágica, testimonio de posibilidad cumplida. Significa también «ser sencillo y sincero en el pensamiento y en la vida", como dice la tercera Intempestiva que era Schopenhauer; se ha de hablar, en consecuencia, de lo vivido y de lo que ha supuesto una orientación vital valiosa: he aquí acepciones de «intempestividad» que legitimarían la propuesta de este ensayo, en el que asumimos nuestra propia voz.

Hay, por otra parte, argumentos estructurales que avalan este intento, como la necesaria «actualidad» de toda hermenéutica que merezca el nombre, así como de toda recepción genuinamente estética: un texto cobra sentido y significación desde las preguntas que le lanzamos y con la sangre que le transferimos, de lo contrario la lectura es mera erudición libresca e impersonal, oficio de docto que acaba jorobado, una cerilla, ya consumida, en el cenicero de las ideas.

Sabemos que se suele repetir que desde el 11-S tenemos a Dostoievski en Manhattan, y así se habla de la presencia reforzada del nihilismo en este mundo globalizado de capitalismo irresponsable, síntoma de la grave crisis que padecemos, pero preferimos insistir en la vigencia de Nietzsche y Dostoievski, dos autores cuyos diagnósticos continúan dándonos que pensar, y cuya comparación sigue mereciendo interés, en parte porque las relaciones existentes entre ellos aún conservan flecos oscuros para la «Nietzsche-Forschung», y en parte porque la obra y la vida de ambos han sido objeto de recientes investigaciones fundamentales, como la modélica de Joseph Frank sobre Dostoievski, que nos incitan a que revisemos con nuevo saber las lecturas del escritor ruso por parte del filósofo alemán desde $1887^{2}$.

2. También sería un motivo de actualidad el que este mismo año 2011 acaba de editarse en bolsillo entre nosotros Humillados y ofendidos en la versión restaurada de Víctor Andresco Kuraitis. Ello 
Y una última precisión: en lo que sigue la tesis doctoral de Paolo Stellino Nietzsche y Dostoieuski: psicología, resentimiento y moral, leída en julio de 2010 en la Universitat de València, nos sirve de soporte y ayuda, así como de indicio de una laguna en la «Nietzsche-Forschung». Desearíamos continuar la senda abierta por Charles A. Miller en su artículo de 1973 «Nietzsche's Discovery of Dostoeivsky» ${ }^{3}$, senda que hemos proseguido investigando la lectura nietzscheana tanto de La logeuse (La patrona) como de la segunda parte de L'esprit souterrain (Apuntes del subsuelo) ${ }^{4}$ : aquí daremos un paso más con la de Humiliés et offensés, puesto que consideramos de relevancia la huella de esta gran novela tanto en lo que se refiere al concepto de psicología como a los de arte y de artista en la obra del Nietzsche de la madurez; asimismo pensamos que su estudio ayuda a perfilar el sentido de varios adjetivos, juicios y párrafos de El Anticristo y de los Fragmentos póstumos de 1888. En nuestra propuesta insistiremos en la posible incidencia que sobre esas tres cuestiones - la psicología, la concepción del artista y los preparativos para El Anticristo - tuvo el muy probable conocimiento por parte de Nietzsche de los textos de E. M de Vogüé en general, y de los comentarios de este sobre Humiliés et offensés de manera muy particular, acicates de la emotiva lectura que hizo el filósofo de esta obra del escritor ruso.

\section{DOCUMENTOS EN TORNO A LA LECTURA NIETZSCHEANA DE HUMILLADOS Y OFENDIDOS}

Recordemos unos datos esenciales: el nombre de Dostoievski aparece citado por vez primera por Nietzsche en una carta a F. Overbeck desde Niza, del 12 de febrero de $1887^{5}$; ese nombre se repite en la carta a H. Köselitz del día siguiente $^{6}$. A ambos amigos les pregunta si conocen a ese escritor y les manifiesta su deseo de hablarles del descubrimiento que acaba de hacer y que le tiene fascinado. De hecho, cuando les vuelve a escribir, les cuenta con detalles ese afortunado hallazgo en las cartas de 23 de febrero y de 7 de marzo, respectivamente ${ }^{7}$. Por ellas sabemos que de Dostoievski no conocía Nietzsche ni el nombre «hasta hace pocas semanas» y, por tanto, que ese zarpazo casual en una librería de Niza de L'esprit souterrain ${ }^{8}$ tuvo que haberse producido a mediados o finales de enero

permite que no tengamos que referirnos solamente a la excelente versión de Augusto Vidal y Luis Abollado que publicaron las Obras Completas de Dostoievski (vol. II, Barcelona: Vergara, 1969), empresa hasta ahora insuperada que editó y prologó el citado profesor Vidal (pp. 413-812), y que obligaba a consultas en las bibliotecas. En lo que sigue remitimos a: F. Dostoievski, Humiliés et offensés, trad. de E. Humbert, Paris: Librairie Plon, 1884, 360 pp. (citado como HeO); Humillados y ofendidos, trad. de V. Andresco, Madrid: Alianza, 2011, 559 pp. (citado como HyO).

3. Nietzsche-Studien 2 (1973), 202-257.

4. «Nietzsche descubre a Dostoievski. Notas sobre la lectura nietzscheana de La patrona»: Estudios Nietzsche 9 (2009), 67-90. «Antropologia filosófica i literatura: la lectura nietzscheana d'Apunts del subsòl de F. Dostoievski»: Quaderns de Filosofia i Ciència 38 (2008), 41-58.

5. KSB VIII 21 (CO V 265).

6. KSB VIII 24 (CO V 267).

7. KSB VIII 27-28 y 41-42 (CO V 270 y 280-281).

8. «Traduit et adapté par E. Halpérine [-Kaminsky] et Ch. Morice, Paris, Librairie Plon, déposé au ministère de l'interieur en novembre 1886». 
de 1887. Esa extraña obra contenía dos diferentes novelas de Dostoievski, La patrona y Apuntes del subsuelo, esta última con muchas lagunas.

Las cartas documentan que durante los primeros meses de 1887 el filósofo se había interesado mucho por el escritor y que ya contaba con informaciones importantes sobre su vida y su obra gracias a otro de sus libros, La maison des morts ${ }^{9}$, esto es, de Memorias de la casa muerta, publicado en Francia con un notable Avertissement o Prefacio redactado por el vizconde Eugène Melchior de Vogüé (pp. I-XVI), experto conocedor de la literatura rusa del XIX y la fuente de los datos sobre Dostoievski que Nietzsche transmite a sus amigos. En la carta a Köselitz concretamente añade otra nueva lectura que acaba de llevar a cabo: «Entretanto, por recomendación de Overbeck, al que le consulté en mi última carta, he leído Humiliés et offensés (lo único que Overbeck conocía), con el mayor de los respetos por el artista Dostoievski» ${ }^{10}$. No se nos ha conservado, por desgracia, la carta en la que Overbeck le recomendó esta novela a Nietzsche, ni sabemos, por consiguiente, los motivos en que pudo basar sus consejos de lectura. Tenemos evidencias, por el contrario, de que sus palabras surtieron efecto y de que el filósofo adquirió un ejemplar de la traducción francesa de esa novela y la leyó con emoción.

En efecto, veinte días después la tarjeta postal a Köselitz de 27 de marzo de $1887^{11}$ documenta que Nietzsche le envía por correo a su amigo esa edición de Humiliés et offensés para corresponderle por lo que este le había enviado a él, la «libre» traducción del ruso al alemán que había hecho Wilhelm Goldschmidt de Erzählungen von F. M. Dostojewskij ${ }^{12}$. Hasta aquí, los datos que el legado del filósofo nos proporciona de su lectura de Humillados y ofendidos. Los estudiosos de su pensamiento estamos, así pues, en una situación muy similar a aquella en la que nos encontramos si queremos comentar la lectura que hizo del relato con el que descubrió a Dostoievski, La patrona, novela corta de la que dejó escrito que era «en realidad una pieza de música, de una música muy extraña, muy no alemana (sehr undeutscher Musik) $»^{13}$. Una indicación solamente, como la citada frase «mit dem grössten Respekt vor dem Künstler Dostoiewsky» en el caso de Humillados y ofendidos ${ }^{14}$, que tantas cosas condensa. Esta parquedad obliga a meditar a fondo el conjunto de textos complementarios de todo el legado nietzscheano, incluyendo su biblioteca, y a releer con suma atención la novela del escritor ruso para así ofrecer una interpretación que haga comprensibles la fascinación de esa lectura y el bello gesto doble de que le hubiera sido recomendada por el estimado Overbeck, por una parte, y de desear tras

9. Es decir, de Souvenirs de la maison des morts, traduit du russe par M. [Charles] Neyroud, Paris: Librairie Plon, 1884

10. La edición que leyó el filósofo, en francés como el título indica, es la traducida por Edmond Humbert, ya citada; parece ser que fue la primera de las novelas de Dostoievski en aparecer en traducción francesa.

11. KSB VIII 50 (CO V 287)

12. Publicado por la editorial Reclam de Leipzig en 1886 y que contenía cinco relatos o narraciones del escritor ruso: Die Whirtin (La patrona), Christbaum und Hochzeit (Un árbol de Navidad y una boda), Helle Nächte (Noches blancas), Weihnacht (Un niño en el árbol de Navidad de Cristo) y Der ehrliche Dieb (El ladrón honrado).

13. KSB VIII 28 (CO V 270).

14. KSB VIII 42. 
su lectura, por la otra, que el compositor Köselitz la conociera, enviándole por correo postal el ejemplar propio ${ }^{15}$.

Los paralelos entre La patrona y Humillados y ofendidos son también muy instructivos, a pesar de sus diferencias de fecha de composición (1847 y 1861) y de número de páginas ( 85 y 400, en la edición dirigida por A. Vidal): en ambos casos nos encontramos con similar perplejidad, pues se trata de textos que han sido muy poco valorados por la crítica, como si fueran obras malogradas, apresuradas y fallidas, $y$ han estado muy asociados al romanticismo y al idealismo, a la novela-folletón de consumo masivo y popular, llena de trucos y suspense, de tramas enrevesadas y teatrales, como si ambas fueran exponentes típicos de todo lo que a Nietzsche tendría que disgustarle hondamente. Y, sin embargo, son estos dos textos, junto con la sesgada adaptación francesa de Apuntes del subsuelo y la traducción de Souvenirs de la maison des morts, la base en la que se cimenta el entusiasmo nietzscheano por la obra de Dostoievski. Algo importante y de clara afinidad personal tuvo que encontrar en aquellos textos, aunque, en efecto, ambos tienen notorias deficiencias y están lejos de esas cuatro grandes cimas de la madurez del escritor, Crimen y castigo, El idiota, Los demonios y Los hermanos Karamázov, de las cuales sabemos a ciencia cierta que el filósofo leyó, extractó y anotó solamente una, Los demonios (Les possédés), y, por otro lado, no se los debe tampoco confundir ni con ese relato genial e incomprendido en su época, Apuntes del subsuelo, que viene a ser como el umbral que da acceso a la plenitud creativa del gran novelista, ni con su testimonio de la estancia en el penal siberiano, Memorias de la casa muerta, uno de los libros más originales y personales del escritor, alabado por la crítica y el público, fundamento de su renovada fama y prueba fehaciente de su excepcional calidad, también a la hora de tratar la cuestión «del criminal».

La crítica histórico-literaria suele conceder pocas líneas a Humillados y ofendidos, como hace, por ejemplo, Edward H. Carr en su lectura crítico-biográfica de Dostoievski 1821-1881, cuando dice que el principal atractivo que tenía el primer número de la revista Vremya (El Tiempo) cuando salió a la calle en enero de 1861 «era la primera parte de una novela de Fiodor, Humillados y ofendidos, una historia difusa, sentimental y melodramática, que hoy solo resulta interesante porque en ella se dibuja su obra posterior, muy superior en calidad $»^{16}$. Augusto Vidal informa que desde la vuelta a la vida civil después de la doble experiencia penal y militar del escritor, y en especial después de su retorno a San Petersburgo, ya en 1859 se puso a planificar una nueva gran novela sobre la vida en la gran ciudad y, a la vez, un libro de memorias sobre sus años de condena en Siberia. Dostoievski tenía que recuperar su prestigio como literato y no podía olvidar el precedente que le encumbró, su opera prima Pobres gentes. Redactó entonces la proyectada novela con prisas, azuzado por la necesidad de entregar los originales a tiempo para su publicación en los números de la revista de su hermano, cosa que repercutió en la insuficiente elaboración del texto y en su inferior calidad,

15. Aunque la mala fortuna hizo que ese envío, a pesar de haber sido empaquetado con todo cuidado, se extraviara, cosa que dejó apenado al filósofo, no por el dinero inútilmente invertido en el correo, sino por la pérdida que ello suponía para su amigo Peter Gast, que se quedaba así sin poder leer en seguida una novela tan conmovedora (KSB VIII 58: carta 832, CO V 293) y sin acompañar al filósofo en sus pasos por la obra del escritor ruso.

16. Trad. de Arturo Licetti, Barcelona: Laia, 1972 (original inglés de 1962), p. 82. 
como el propio escritor reconoció en 1864, lo cual motivó que alterara muchos pasajes melodramáticos de la novela cuando a finales de 1861 la editó en volumen autónomo. En la pintura de las tragedias de la vida moderna en la gran ciudad «estudia Dostoievski la psicología de sus personajes de manera sumamente peculiar: no en su desarrollo gradual sino en sus manifestaciones en los momentos decisivos de su vida ${ }^{17}$. Podríamos decir, así pues, que la novela no es un exponente de psicología evolutiva sino de psicología de la decisión, de las opciones vitales. A pesar de todos sus fallos, esta novela fue tenida en alta estima por Dobroliúbov, por Saltikov-Schedrín y por Tolstói ${ }^{18}$. Una de sus características principales radica en que "contiene muchas páginas de carácter autobiográfico", en especial al describir al escritor Iván Petróvich y el éxito de su primera novela, las críticas positivas de B. (Bielinski), el duro trabajo y las difíciles condiciones económicas de la vida del literato, su soledad afectiva, las tensas relaciones con los editores, meros empresarios, ansiosos de aumentar sus ganancias, etcétera ${ }^{19}$.

Cuando Dostoievski regresó a la capital, sus hábitos narrativos propios de los años cuarenta ya habíann quedado anticuados al inicio de la década de los sesenta, la de la liberación de los siervos, de ahí el efecto exagerado y trasnochado que dicen que causó su manera de mantener la intriga mediante los sobados procedimientos de la novela-folletón, finalizando los sucesivos capítulos en agudo suspense que mantenía en vilo a los lectores. Leonid Grossman explica que ya el título Humillados y ofendidos anunciaba el tema central de la obra, su género y su estilo, el de la novela social, pero tratado ahora con múltiples planos y contrastes entre el vicio y la virtud, y con la figura central de un héroe demoníaco que influye sobre el destino del resto de personajes. De hecho, la novela fue leída con pasión por el público (y todavía sigue siendo de muy grata lectura), pero la crítica no dejó de subrayar la debilidad de su estructura y la irrealidad del asunto. Dobróliubov la consideró la mejor obra literaria del año, llena de ideales y de compasión humanitaria, pero fallida desde el punto de vista estético, y poco oportuna desde el político, ya que los buenos son todos débiles de voluntad e incapaces de acciones revolucionarias. Desde una tendencia ideológica opuesta Grigoriev criticaba sus contrastes literarios irreconciliables, su mezcla de fuerza en el sentimiento y de ineptitudes pueriles, de escenas falsas y personajes librescos, excepto en el caso de Nelly: en resumen, gran ignorancia de la vida real, pero enorme fuerza en todo lo referente al mundo de los sueños y de lo excepcional ${ }^{20}$. A ello el investigador ruso añade que por entonces Dostoievski se encontraba en un momento de búsqueda y en una encrucijada, dedicado a experimentos que no le acababan de salir bien, tratando de seguir las reglas de la novela-folletón melodramática de un Eugène Sue, el autor de Mystères de Paris, con tipos convencionales y simplificados, unos buenos y otros malos, descritos rápidamente mediante cuatro brochazos, pero atribuyéndoles aspectos secretos y misteriosos, y la consabida oposición entre la aristocracia pervertida y el pueblo llano explotado. El resultado, aunque fuera de poca calidad artística, se salvaba por sus objetivos morales y su actualidad social. El propio Dostoievski

17. Augusto Vidal, «Prólogo», en F. M. Dostoievski, Obras completas, vol. II, cit., p. 16.

18. Cf. ibid., p. 17.

19. Cf. ibid., p. 16.

20. Cf. L. Grossman, Dostoüevski, trad. de M. Kahn, Paris: Parangon, 2003, p. 217. 
reconocía que su novela se había publicado de forma precipitada y descuidada, con personajes librescos que parecían marionetas, pero afirmaba que, no obstante, contenía poesía, con dos o tres pasajes poderosos y unas cincuenta páginas de las que se sentía orgulloso. Grossman se suma a la lista de los críticos que valoran la creación de la figura de Nelly como víctima, uno de los retratos de niños más logrados de toda la obra del escritor ${ }^{21}$. En efecto, en seguida pensamos en la muerte de otro infante, el personaje de Iliushka de Los hermanos Karamázov, como también es frecuente relacionar al joven príncipe Aliosha con otro príncipe, Mishkin, el protagonista de El idiota ${ }^{22}$, o a Natasha con figuras femeninas de otras novelas de la madurez del escritor, desde la Dunia de Crimen y castigo a la Nastasia de El idiota, por no citar obvios ejemplos de Los hermanos Karamázov, de El jugador o de Apuntes del subsuelo.

Ciertamente, como ha indicado Joseph Frank, los conocedores de la obra de Dostoievski tienen la curiosa impresión de que Humillados y ofendidos es como una antología hecha con fragmentos de sus obras maestras posteriores, pero elaborada por un compilador que ignora las complejidades de esos libros. En este sentido lo más interesante son sus anticipaciones, pero eso solo lo podemos decir ahora, mucho después de la muerte de su autor, de manera retrospectiva; para los mejores lectores de 1861 era una novela que estaba por debajo de las más elementales exigencias de la crítica estética, como dijeron Evgenia Tur y el influyente Dobroliubov ante este folletón sentimentalista y lacrimógeno ${ }^{23}$. Para el profesor norteamericano Humillados y ofendidos tiene una fractura interna entre su pretensión de continuar con los planteamientos humanitarios de la novela social y filantrópica (unos pobres inocentes, humillados por un aristócrata despiadado) y la mostración de la raíz psicológico-ideológica de los diferentes conflictos que tienen lugar en las relaciones interpersonales, seguramente porque el escritor aún no había acabado de superar su primera etapa y no conseguía presentar personajes que supieran enfrentarse sin ingenuidades al desafío del egoísmo perverso de los poderosos. El fracaso del escritor Iván Petrovich y su muerte inminente en un hospital así lo manifiestan ${ }^{24}$. No obstante, hay ejemplos de amor activo que superan el «egoísmo del sufrimiento» con sus correspondientes muestras de masoquismo y de sadismo, de frustración y de resentimiento, tanto en el caso de Natasha, como en el de su padre y en el trágico de la desamparada huérfana Nelly. Estos rasgos de crítica al romanticismo ingenuo y al idealismo sentimental se alejan de la novelafolletón progresista y socialista y apuntan hacia un nuevo tipo de novela, la novela-tragedia de ideas del maduro Dostoievski.

Ahora bien, en marzo de 1887 Nietzsche tenía pocas informaciones sobre la vida y la obra del escritor ruso, quizá Humiliés et offensés fue el segundo o tercer libro que le leyó, y, no obstante, afirmó de inmediato su máximo respeto por este artista, a pesar de tratarse de una obra en cierto modo fallida e inmadura, "con

21. Cf. ibid., pp. 218-219.

22. George Steiner ya dijo que Humillados y ofendidos «es en muchos aspectos un esbozo preliminar de El idiota», cf. G. Steiner, Tolstoi o Dostoieuski (1959), trad. de A. Bartra, México: Era, 1968, p. 148.

23. Cf. J. Frank, Dostoievski. La secuela de la liberación, 1860-1865 (1986), trad. de J. J. Utrilla, México: FCE, 1993, pp. 149-150.

24. Cf. ibid., pp. 151-158. 
mucho, la más débil de las seis grandes novelas post-siberianas de Dostoievski», como ha dicho Frank ${ }^{25}$. ¿Qué pudo encontrar en ella que le entusiasmara tanto? ¿Muchas similitudes con lo más valioso que ya había hallado en los dos relatos de L'esprit souterrain? En efecto, y muchas cosas más, como quisiéramos mostrar de manera detallada. Conviene insistir en que esa lectura no fue aislada o esporádica, sino que se dio en un contexto de conocimiento de varias obras de un autor profundo, cada vez más estimado por el filósofo.

\section{DOSTOIEVSKI, UN PSICÓLOGO MAGISTRAL Y EMINENTE, CON EL QUE «YO ME ENTIENDO»}

Si revisamos los juicios que Dostoievski le merece a Nietzsche desde que comenzó a leerlo, sorprende la reiteración de una misma tesis: «Excepto Stendhal, nadie me ha causado tanto contento [Vergnügen] y sorpresa: un psicólogo con el que 'yo me entiendo'». ${ }^{26} \mathrm{Si}$ añadimos las declaraciones sobre el escritor que contiene la correspondencia del filósofo, por ejemplo, en las cartas $804,812,814,845,847,872,1134$ y 1151 de 1887 y $1888^{27}$, entonces de esos testimonios se obtiene un común denominador, que Nietzsche precisó en el aforismo 45 de Crepúsculo de los ídolos: «Dostoievski, el único psicólogo, dicho sea de paso, del que yo he tenido que aprender algo ${ }^{28}$. A ello se añaden los fragmentos póstumos preparatorios para El Anticristo en los que Nietzsche critica la pobreza psicológica de Renan al interpretar a Jesús de Nazareth como héroe y como genio, y reinvindica la perspicacia 'cristológica' de Dostoievski, psicólogo magistral, y la figura de 'el idiota', adjetivo que, como se sabe, él usa a conciencia en su libro' ${ }^{29}$. He aquí, pues, por qué conviene estudiar Humillados y ofendidos con el expreso propósito de identificar y extraer alguna de las lecciones de psicología que Nietzsche pudo obtener de su lectura de esa novela. No se debe olvidar tampoco que lo único que dejó escrito de esa concreta experiencia es el máximo respeto que sentía por el artista Dostoievski. Ya tenemos esbozadas, por tanto, las principales pistas a seguir.

El campo se acota más todavía si recordamos que la estima por el escritor ruso se afirma en un contexto muy determinado: «el eminente psicólogo Dostoievski, con el que ni siquiera el más moderno París tiene alguien que se le parangone en lo que hace a la agudeza de análisis $»^{30}$. Téngase en cuenta que quienes quedan postergados a un segundo lugar son nada menos que los escritores franceses del París de ese momento, "psicólogos tan curiosos y a la vez tan delicados» como Paul Bourget, Pierre Loti, Gyp, Meilhac, Anatole France, Jules Lemaître, Guy de Maupassant... ${ }^{31}$, autores que Nietzsche reconocía, citaba en sus libros, cartas y cua-

25. Ibid., p. 148 .

26. KSB VIII 24: carta 800, 13 de febrero de 1887 (CO V 267).

27. Cf. nuestro artículo «La intensa relación de Nietzsche con Dostoievski»: La Torre del Virrey 69 (verano de 2009), pp. 1-8.

28. CI, Madrid: Alianza, 1998, p. 129.

29. Cf. P. Stellino, «Ein Vergleich zwischen Nietzsches Der Antichrist und Dostojewskijs Der Idiot»: Nietzscheforschung 14 (2007), 203-210.

30. KSB VIII 39: carta 812 (CO V 278).

31. Cf. EH «Por qué soy yo tan inteligente» $\mathbb{S}$ 3, Madrid: Alianza, 1998, p. 49. 
dernos, y cuyas obras leía y tenía en su biblioteca; los prefería a los grandes maestros de la generación anterior (Taine, Baudelaire, los Goncourt, Flaubert...), con la excepción del extraordinario Stendhal. En este contraste entre el escritor ruso y los parisinos, otra carta, justo después de informar que acaba de leer Humillados $y$ ofendidos, puntualiza esto: «Me doy cuenta también de cómo la generación más joven de novelistas parisinos está completamente tiranizada por la influencia de Dostoievski y por los celos con respecto a él (por ejemplo, Paul Bourget)»32.

El hecho de que se refiera a los «celos» y de que las novelas que el filósofo conocía de Bourget contasen historias de $\operatorname{amor}^{33}$, bien pudiera ser un indicio de la influencia que detectaba de Humillados y ofendidos, ya traducida al francés en 1884. Quisiéramos insistir en que Nietzsche subraya la audacia y la fuerza superior del artista Dostoievski después de confesar que ha leído esa novela suya, interpretada por muchos como un condensado de lo que sería la «moral de esclavos». Pensamos, por tanto, que la limitación a Apuntes del subsuelo y Los demonios en los comentarios e interpretaciones sobre la huella de Dostoievski en el filósofo es una proyección retrospectiva en parte desenfocada, porque no argumenta desde todas las premisas de los juicios nietzscheanos; con la exclusiva referencia a la muy recortada edición francesa de Apuntes del subsuelo no acaban de comprenderse bien los «celos» de los jóvenes escritores parisinos por el autor ruso, celos detectados por Nietzsche expresamente en el caso de Paul Bourget.

Sobre este novelista y crítico literario, cuya novela de 1887, André Cornélis, estaba dedicada a H. Taine, el filósofo se volvió a manifestar en carta al historiador francés, la número 872, explicándole por qué no le gustaba dicho libro:

A $M r$. Bourget no le será nunca posible hacer creíble un agujero fisiológico real en el pecho de un hombre (algo así es para él meramente quelque chose arbitraire [una cosa arbitraria], de lo cual es de esperar que su delicado gusto lo mantenga alejado de ahorta en adelante. Pero parece que el espíritu de Dostoievski no deja en paz a estos novelistas parisinos $)^{34}$.

Este comentario sugiere una estrategia de lectura que podría resultar de interés: comparar críticamente las novelas de Dostoievski que Nietzsche conocía en el verano de 1887 con las lecturas que había hecho de las novelas de Paul Bourget, concretamente de André Cornélis, que formaba parte de su biblioteca personal. Es bien sabido que el filósofo estimaba la obra crítica de este curioso escritor de oscilante biografía, cuyos dos volúmenes de Essais de psychologie contemporaine [Ensayos de psicología contemporánea] ${ }^{35}$ y Nouveaux essais de psychologie contemporaine [Nuevos ensayos de psicología contemporánea] ${ }^{36}$ tanta incidencia tuvieron en el pensamiento nietzscheano posterior a la redacción del Zaratustra. En este sentido, la comparación con la perspicacia psicológica de Dostoievski todavía resalta con mayor fuerza. Por eso echamos de menos una lectura también de la

32. KSB VIII 41-42: carta 814 (CO V 281), citamos con alguna modificación.

33. Cf. Un crime d'amour, Paris: A. Lemerre, 1886, y André Cornélis, Paris: A. Lemerre, 1887.

34. KSB VIII 106 (CO V 329), traducción que modifico en parte.

35. Paris: A. Lemerre, 1883.

36. Paris: A. Lemerre, 1885. 
obra novelística de Bourget que Nietzsche llegó a conocer y su ceñida comparación crítica con sus lecturas y juicios sobre las obras de Dostoievski, pensamos que esta labor enriquece la Nietzsche-Forschung ${ }^{37}$ : temas como «el parisino europeo», los literatos como anatomistas y fisiólogos, la enfermedad de la voluntad y los estilos de la décadence, sabiamente propuestos por G. Campioni, podrían analizarse en esa ceñida comparación que deberíamos hacer.

Quisiéramos precisar otro detalle: durante ese verano de 1887 Meta von Salis-Marschlins visitó al filósofo en Sils-Maria y en el libro que le dedicó dice que en uno de los paseos que ambos emprendieron Nietzsche le había confesado que

Leyó con ojos humedecidos Humillados y ofendidos, obra aún más profunda [que la narración Der Nachsommer de Adalbert Stifter], más humilde, una obra humillante por la opresión y el aplastamiento de sus héroes, casi insoportable para el orgullo de un ser humano. Él —esto es lo importante-condenaba toda una serie de sentimientos en su grado extremo, no porque no los tuviera, sino al contrario, porque los tenía y conocía su peligro ${ }^{38}$.

Este comentario que demuestra la fuerza de la emotiva lectura de esta apreciada novela deja por desgracia sin especificar a qué sentimientos extremos se referían Nietzsche y la autora de esta nota: solo se apunta hacia el sufrimiento de los humildes y al hundimiento de los héroes. Hemos de clarificar, por tanto, el resto de aspectos vertebrales de esa lectura que casi hacía llorar al filósofo.

\section{LA INTERPRETACIÓN DOSTOIEVSKIANA DEL VIZCONDE DE VOGÜÉ: DOSTOIEVSKI COMO PSICÓLOGO, COMO ARTISTA-FILOSÓFO Y CRISTIANO. HUMILLADOS Y OFENDIDOS, ESBOZO PRELIMINAR DE EL IDIOTA Y FUENTE DE EL ANTICRISTO}

En nuestra opinión, los textos de E. M. de Vogüé sobre el novelista ruso ${ }^{39}$, que es bastante probable que el filósofo conociera, ofrecen argumentos a favor tanto

37. La lectura nietzscheana de Un crime d'amour está documentada, por ejemplo, en la carta a Franz Overbeck de 10 de abril de 1886, en la que dice que esa novela, genuina y selecta «literatura de cámara», es el gran éxito de ese año en literatura francesa, y que ve en ella el "primer encuentro de las dos corrientes más espirituales del pesimismo, la del schopenhaueriano (con la 'religión de la compasión') y la del stendhaliano ('con su afilada y cruel psicología')», KSB VII 171: carta 684 (CO V 158). Sobre las relaciones de Nietzsche con la obra de Bourget es importante el capítulo «El viaje a Cosmópolis del señor Nietzsche», pp. 267-300 del inagotable libro del profesor G. Campioni, Nietzsche y el espíritu latino, trad. y prólogo de Sergio Sánchez, Buenos Aires: El cuenco de plata, 2004. También es muy orientativo el lúcido ensayo de Franco Volpi «Le nihilisme comme logique de la décadence: Nietzsche lecteur de Bourget», en Jean-François Mattéi, Nietzsche et le temps des nibilismes, Paris: PUF, 2005, pp. 97-119.

38. Philosoph und Edelmesch: Ein Beitrag zur Charakteristik Friedrich Nietzsches, Leipzig: Naumann, 1997, pp. 40-59.

39. Se trata de los artículos que aparecieron en la Revue des Deux Mondes en 1885-1886, revista muy apreciada por Nietzsche, luego recogidos en el libro Le roman russe, de 1886, así como el prólogo o Avertissement a la traducción francesa de Souvenirs de la maison des morts y el artículo «Un nouveau roman de Dostoievski», en Journal des Débats, 2 de abril de 1887, publicación también estimada por Nietzsche, que reproduce en cierto modo otro Avertissement, el que precede a la traducción francesa de L'idiot, textos que suman en conjunto un centenar de páginas dedicadas a comentar la vida y la obra del novelista. 
de la grandeza psicológica de Dostoievski, como del respeto que Nietzsche sentía por el autor de Humillados y ofendidos en cuanto artista trágico y en cuanto filósofo, y permiten abordar la importante cuestión de considerar esta novela, sobre todo en los personajes del príncipe Aliocha y de la niña Nelly, la cual sufre crisis nerviosas y epilépticas y se inmola también un Viernes Santo, como una inequívoca fuente indirecta de los conocimientos por parte del filósofo de lo que luego será la figura 'cristológica' de El idiota, y se convierte así en una de las principales influencias en la gestación de El Anticristo. Veámoslo en los textos.

En efecto, en Le roman russe [La novela rusa] ${ }^{40}$, en el capítulo dedicado a Dostoievski, titulado «La religion de la souffrance [la religión del sufrimiento] ${ }^{41}$, el vizconde ya comenta que, a diferencia de otros escritores rusos amantes de la naturaleza y el campo, este novelista urbano solo les prestará una atención distraída, ya que «psychologue, l'âme humaine retiendra toute sa vue, ses paysages préférés seront les faubourgs des grandes villes, les rues de misère... les jeux timides entre les 'humiliés' et les 'offensés' [psicólogo, el alma humana concentrará toda su visión, sus paisajes preferidos serán los suburbios de las grandes ciudades, las calles miserables... los tímidos juegos entre los 'humillados' y los 'ofendidos'] ${ }^{42}$. La terrible experiencia del condenado a muerte al subir al cadalso será, según de Vogüé, una de las más insistentemente repetidas en las diferentes novelas del escritor que la tuvo que sufrir, «et il s'acharnera a l'étude psychologique du condamné qui va mourir; remarquez l'intensité particulière de ces pages, on y sent l'hallucination d'un cauchemar qui habite dans quelque retraite douloureuse du cerveau [y se obstinará en el estudio psicológico del condenado a muerte; nótese la particular intensidad de esas páginas en las que se siente la alucinación de la pesadilla que mora en cada doloroso rincón del cerebro]» ${ }^{43}$. Del mismo modo, de los años de estancia en el penal, rodeado de criminales a los que pudo observar pacientemente, «il en résulte d'incomparables études psychologiques [se derivan estudios psicológicos incomparables] $\gg^{44}$. Por otra parte, en el Avertissement que redactó como Prólogo a la traducción francesa de Souvenirs de la maison des morts ${ }^{45}$, de Vogüé repite las palabras de un amigo del escritor, condenado también en Siberia: «son talent bénéficie de ses souffrances, elles développèrent en lui le sens de l'analyse psychologique [su talento se benefició de sus sufrimientos, que desarrollaron en él el sentido del análisis psicológico]» ${ }^{46}$. De nuevo en Le roman russe, y hablando esta vez de Crimen y castigo, el crítico francés lo considera «la plus profonde étude de psychologie criminelle qui ait été écrite depuis Macbeth [el estudio más profundo de psicología criminal que se haya escrito desde Macbeth]» ${ }^{47}$. «Le drame, purement psychologique, est tout entier dans le combat entre l'homme et son idée [El drama, puramente psicológico, se encuentra

40. Paris: Plon, 1886.

41. E. M. Vogué, Le roman russe, cit., pp. 203-277.

42. Ibid, pp. 205-206.

43. Ibid, p. 222.

44. Ibid, p. 226.

45. F. Dostoievski, Souvenirs de la maison des morts, cit..

46. Ibid, p. 11.

47. Ibid, p. 246. 
por entero en el combate entre el hombre y su idea]» ${ }^{48}$. En una palabra, para él Dostoievski es «le psychologue dramatique [el psicólogo dramático]» ${ }^{\star 9}$, un "psychologue incomparable [un psicólogo incomparable] $»^{50}$. La coincidencia con los juicios de Nietzsche es, pues, muy notable.

En la opinión del estudioso francés la novela Humillados y ofendidos era, entre otras cosas, una especie de autobiografía del artista y de su amor incondicional por el trabajo de novelista, creador de personajes que mueven al llanto: "c'est avec le souvenir de ces premières ivresses qu'il fera parler un des personages tirés de lui-même, le romancier qui figure dans Humiliés et offensés [es con el recuerdo de estas primeras ebriedades con el que hará que hable uno de los personajes sacados de él mismo, el novelista que aparece en Humiliés et offensés] ${ }^{51}$, y de Vogüé cita a continuación un pasaje de la novela que seguramente interesó al Nietzsche que deploraba que sus pensamientos, ya escritos y editados, dejaban de ser pájaros vivos:

iAy! Si alguna vez he sido feliz, no fue en los primeros momentos embriagadores de mi éxito, sino cuando aún no había leído ni enseñado a nadie mi obra. En aquellas largas noches de exaltadas esperanzas, de sueños y de apasionado amor al trabajo, cuando vivía con mi imaginación, con los personajes que había creado, como si me fuesen familiares, como si existieran en realidad. Los amaba, me alegraba y entristecía con ellos y a veces hasta lloraba lágrimas sinceras por mi modesto héroe ${ }^{52}$.

Este artista es, a su vez, y en mayor y mejor medida que lo era el personaje de Ordínov en La logeuse, un pensador, un genuino filósofo, muy similar en algunos puntos de su talante al propio Nietzsche. Este artista medidativo es una presentación indirecta del propio filosofar de Dostoievski. En efecto, una carta a su hermano sobre los meses que pasó en una cárcel de Moscú tras las detenciones de varios miembros del círculo de Petraschevski, antes del traslado al penal siberiano al que fue condenado, pudo confirmarle a Nietzsche el parentesco o la profunda afinidad que le unían con el escritor:

Pendant cinq mois j'ai vécu de ma propre substance, c'est a dire de mon seul cerveau et de rien autre... Penser perpétuellement et seulemenmt penser, sans aucune impression extérieure pour renouveler et soutenir la pensée, c'est pesant... J'étais comme sous une machine à faire le vide, d'où on retirait tout l'air respirable ${ }^{53}$.

48. Ibid, p. 247.

49. Ibid, p. 261.

50. Ibid, p. 267.

51. Ibid, p. 208.

52. Cf. HyO I, 5, p. 57, que bien se puede comparar con MBM $\$ 296$, Madrid: Alianza, 1997, p. 270.

53. Ibid, p. 220. He aquí la traducción entera de este fragmento epistolar, en versión de Selma Ancira: «Hace ya cinco meses, casi completos, que vivo de mis propios recursos, es decir, solo de mi cabeza y nada más. Por lo pronto la máquina todavía no se ha descompuesto y funciona. Por otra parte es un pensar eterno, pensar y solo pensar, sin ninguna impresión del exterior para regenerar y alimentar el pensamiento - ies difícil! Todo yo estoy como dentro de una bomba de la cual están extrayendo el aire» (F. Dostoievski, Cartas a Misha [1838-1864], Barcelona: Grijalbo-Mondadori, 1995, p. 151). 
De Vogüé reconoce en este artista la gran solidez de la estructura de sus creaciones, y el hecho de que sabe sacrificar los diferentes materiales que utiliza a la impresión de conjunto, a la belleza de las líneas generales, con lo cual tenemos aquí un rasgo diametralmente opuesto a aquel que, según Bourget y el mismo Nietzsche, es una característica del arte decadente, a saber, la fragmentación, el aislamiento de los capítulos, de las frases y de las palabras, la atomización y las miniaturas aisladas: «La structure est si solide, les matériaux si simples et si bien sacrificés à l'impression d'ensemble, qu'un fragment détaché perd toute valeur; il ne signifie pas plus que la pierre arrachée d'un tempple grec, où toute la beauté reside dans les lignes générales [La estructura es tan sólida, los materiales tan simples y tan bien sometidos a la impresión de conjunto, que un fragmento aislado pierde todo su valor; no significa más que la piedra arrancada de un templo griego, en el que la belleza entera se halla en las líneas generales]» ${ }^{54}$. No obstante, Dostoievski es también un maestro en «'art d'éveiller avec un ligne, un mot, des résonnances infinies, des séries de sentiments et d'idées [el arte de producir con una línea, con una palabra, infinitas resonancias, conjuntos de sentimientos e ideas]», como Nietzsche deseaba hacer en cada uno de su aforismos ${ }^{55}$.

Sobre el arte del escritor Dostoievski, el vizconde francés tiene apreciaciones y metáforas que pudieron resultarle muy oportunas y convincentes al filósofo a la hora de acrecentar su estima por el novelista y sus respetos por el artista: por ejemplo, el estilo con el que Dostoievski escribe es como el teclado de un órgano, las estrechas teclas de las que parece que sale el sonido están unidas por conductos invisibles al vasto corazón del instrumento, al depósito de armonía en el que surgen las tormentas... ${ }^{56}$. Por lo demás, los lectores, al acabar sus novelas, conocemos a los personajes como su hubiéramos convivido con ellos, a pesar de lo poco que el autor nos cuenta de sus vidas, pues «décidément l'écrivain est surtout puissant par ce qu'il ne dit pas: nous lui sommes reconnaissants de tout ce qu'il nous laisse deviner [en definitiva, el escritor es poderoso sobre todo por lo que no dice: le estamos agradecidos por todo lo que nos deja adivinar] ${ }^{57}$. Este escritor, por otra parte, no se dedica a descripciones minuciosas y a contar anécdotas diversas y entretenidas, ya que es un «écrivain... envahi par les idées et les formes [escritor... poseído por las ideas y las formas] $\aleph^{58}$, es decir, es un pensador, un filósofo («il avait la finesse philosophique [poseía la finura filosófica] $\aleph^{59}$, incluso un metafísico («ce métaphysicien ${ }^{60}$ ). Dostoievski es el extraño extranjero «qui va révolutionner toutes nos habitudes intellectuelles [quer va a revolucionar todos nuestros hábitos intelectuales] ${ }^{61}$. De ahí que leerlo requiera «un effort d'attention et de mémoire égal à celui qu'exigerait un traité de philosophie [un esfuerzo de atención y de memoria igual al que exigiría un

54. Ibid, p. 215.

55. Ibid.

56. Ibid., pp. 225-226

57. Ibid., p. 216.

58. Ibid., p. 224.

59. Ibid., p. 217

60. Ibid., pp. 218-242.

61. Ibid., p. 203. 
tratado de filosofía]» ${ }^{62}$. Él es, en efecto, "un philosophe [un filósofo]» ${ }^{63}$. De ahí la singularidad de su novelística. Como dice el especialista francés al transcribir el juicio de otro crítico literario ${ }^{64}$, la superioridad del escritor ruso reside en que «il possède deux facultés qui sont rarement réunies chez nos écrivains: la faculté d'évoquer et celle d'analyser [posee dos facultades que rara vez se hallan reunidas en nuestros escritores: la facultad de evocar y la de analizar]». ${ }^{65}$ En el «Ensayo de autocrítica» a la tercera edición de El nacimiento de la tragedia Nietzsche también advierte que su libro es para artistas excepcionales que cuenten con capacidades analíticas y retrospectivas ${ }^{66}$.

Al comentar la estructura de Humillados y ofendidos de Vogüé explica críticamente, pero con certera precisión:

L'exposition trop lente, l'action dramatique double choquent toutes nos habitudes de composition; au moment où nous nous intéressons à l'intrigue, il en surgit une seconde à l'arrière-plan, dinstincte. Et qui semble copiée sur la première. Je croirais volontiers que l'écrivain a cherché dans ce dédoublement un effet d'art très-subtil, par un procédé emprunté à ceux des musiciens; le drame principal éveille dans le lointain un écho; c'est le dessin mélodique de l'orchestre, transposant les choeurs qu'on entend sur la scène. Ou bien, si l'on préfère, les deux romans conjugués imitent le jeu de deux miroirs opposés, se renvoyant l'un à l'autre la même image. C'est trop de finesse pour le public [La exposición demasiado lenta, la acción dramática doble chocan contra todas nuestras formas habituales de composición; en el momento en el que nos interesamos por la intriga, entonces surge desde el trasfondo otra, diferente. Que, además, parece que se ha copiado de la primera. Yo creería gustosamente que en este desdoblamiento el escritor ha buscado un efecto artístico muy sutil, que ha tomado prestado de los que utilizan los músicos; el drama principal produce en el secundario un eco; es el dibujo melódico de la orquesta, trasponiendo los coros que se escuchan en el escenario. O bien, si se prefiere, las dos novelas conjugadas imitan el juego de dos espejos opuestos, enviándose el uno al otro la misma imagen. Es demasiada finura para el público $]^{67}$.

En este sentido, también se podría decir de esta novela que es «una música muy extraña, muy poco alemana» y que su autor demuestra una «finesse d'esprit [finura espiritual]» como el mejor Pascal. En cierto modo parece un verdadero drama musical, una genuina tragedia griega, una pieza de doble entramado, sutilmente compuesta, en la que su autor parece inspirado por los procedimientos de los músicos ${ }^{68}$.

62. Ibid., p. 253

63. Ibid., p. 268.

64. Se refiere, sin citarlo, a André Mori, que el 14 de enero de 1885 publicó un artículo titulado «Dostoievski» en el Journal des Débats, en el que decía que el escritor ruso tenía las capacidades analíticas de Stendhal y la imaginación y la facultad de evocar de Zola, cf. la nota 162, p. 99, del ya citado libro de G. Campioni Nietzsche y el espíritu latino.

65. Avertissement a la trad. francesa de Souvenirs de la maison des morts, p. 6.

66. OC I, p. 330.

67. Ibid., pp. 240-241.

68. Es probable que de Vogüé hubiera basado su juicio en una carta del mismo Dostoievski sobre su manera de escribir Apuntes del subsuelo, cuyas partes complementarias transponían un 
Aún hay otro rasgo en la novelística dostoievskiana analizada por de Vogüé que puede resultar decisivo para apreciar su talante artístico, a saber, su dimensión verdaderamente trágica, como ya hemos insinuado. Por ejemplo, cuando el estudioso francés compara las obras de los novelistas rusos con la pintura de tres artistas franceses, entonces considera que la de Dostoievski guarda semejanzas con «l'âpreté tragique de Millet [la severidad trágica de Millet]»" su primera novela es «une tragédie si simple et si navrante [una tragedia tan sencilla y tan desconsoladora]» ${ }^{70}$, repleta de cuadros llenos de realidad «avec une vigueur tragique [con un vigor trágico] $\gg^{71}$. La experiencia penal tan atroz que sufrió el escritor le concede «une physionomie tragique entre tous les écrivains [una fisionomía trágica entre todos los escritores] ${ }^{72}$. Sus recuerdos carcelarios son una serie de «tableaux tragiques [cuadros trágicos]»" ${ }^{73}$. El personaje de Natasha de Humillados y ofendidos merece esta presentación: «est la passion incarnée, dévouée et jalouse; elle parle et agit comme une victime des tragédies grecques, tout entière en proie à la Vénus fatale [es la pasión encarnada, sacrificada y celosa; ella habla y actúa como una víctima de las tragedias griegas, que está totalmente en las manos de la Venus fatal] $\gg^{74}$. La fuerza que empuja a Raskólnikov es «comme la fatalité dans les tragédies antiques [como la fatalidad en las tragedias antiguas] $] »^{75}$. El genio del autor ruso, en suma, está «torturé par les visions tragiques [torturado popr las visiones trágicas] $\aleph^{76}$. Dostoievski es, en conclusión, el gran novelista trágico del XIX, como lo fueron en su teatro Shakespeare en la época isabelina, o Racine en el clasicismo francés, convirtiéndose así en uno de los más grandes seguidores de los trágicos atenienses, en un verdadero poeta trágico ${ }^{77}$. Este juicio estético no podía dejar indiferente al autor de El nacimiento de la tragedia, obra que en 1886 Nietzsche había releído a fondo para redactar el Ensayo de autocrítica, el prólogo para la nueva edición.

Desde el punto de vista que considera Humillados y ofendidos como un precedente de El idiota y, en este sentido, como una de las fuentes de El Anticristo nietzscheano, tesis en la que deseamos insistir, el capítulo de Le roman russe tiene también sugerencias muy interesantes: en las novelas de Dostoievski, dice el crítico francés, es frecuente la opción que toman varios personajes en favor del sufrimiento (como aquí hace Natasha de manera explícita, pero no por masoquismo, sino porque el tiempo ha de madurar las cosas que son difíciles de asumir, ha de cicatrizar las heridas, como el fracaso de una relación amorosa, o el hecho de que una mujer joven decida por su cuenta y riesgo qué hacer con su vida y con su cuerpo, al margen de las opiniones de sus padres y del qué dirán),

mismo tema, al igual que hacen los músicos en su exposición de un mismo aire o melodía, cf. nuestro artículo «Una lectura antropológica de Memorias del subsuelo de Dostoievski»: Thematha 39 (2007), 179-207.

69. Ibid., p. 204

70. Ibid., p. 210.

71. Ibid., p. 213.

72. Ibid., p. 217.

73. Ibid., p. 233.

74. Ibid., p. 242.

75. Ibid., p. 248.

76. Ibid., p. 279.

77. Cf. G. Steiner, op. cit., p. 14. 
y eso le permite mostrar el sentido místico que el hombre del pueblo en Rusia atribuye al sufrimiento, que goza así de valor por sí mismo, gracias a su virtud propiciatoria ${ }^{78}$. En este momento de Vogüé añade: «Ici se retrouve cette idée de l'Antechrist, inseparable du pouvoir temporel pour une partie de ce peuple, pour les innombrables sectaires du raskol [Aquí se vuelve a encontrar esta idea del Anticristo, que es inseparable del poder temporal para una parte del pueblo ruso, para los innumerables miembros de la secta de los viejos creyentes]». El tradicionalista francés destaca también la presencia de los Evangelios en el penal siberiano, y comenta los recuerdos del escritor sobre sus compañeros de destino con estas palabras: "Ce gens-là viennent tout droit des Actes des apôtres, despuis le paysan du raskol qui cherche la 'souffrance', jusqu'à l'écrivain qui raconte la sienne avec une douceur résignée [Esas gentes proceden directamente de los Hechos de los apóstoles, desde el viejo creyente campesino que busca el 'sufrimiento' hasta el escritor que cuenta el suyo propio con una dulzura resignada]». Téngase presente que los personajes de Humillados y ofendidos también incluyen un escritor que relata su dolor con suave e irónica resignación, y un conjunto de personajes que parecen sacados del cristianismo primitivo, como los padres de Natasha, Nikolái y Anna, o el viejo Smith y su hija y su nieta, lectores todos del Nuevo Testamento, sobre todo de los Evangelios, de los que citan sentencias fundamentales ${ }^{79}$. Por otra parte, los rasgos de «sublimidad, enfermedad e infantilismo» que caracterizarían el 'idiotismo' de Jesús ${ }^{80}$ se prefiguran ya en el personaje del príncipe Aliosha, antecedente directo del príncipe Mishkin en tantas cosas (nobleza, ingenuidad, infantilismo, veracidad, etc.) y en la niña Nelly, gravemente enferma del corazón, propensa a ataques epilépticos, víctima sacrificial que redime a Natasha y logra su reconciliación familiar, sobre todo con la figura orgullosa y judicialmente humillada de su conmovido padre ${ }^{81}$.

78. E. M. Vogüé, op. cit., p. 228.

79. Cf. HyO, pp. 35, 509, 510, 557

80. Cf. AC $\$ 31$, Madrid: Alianza, 1997, p. 67.

81. En este sentido, y como prefiguración de las gentes de los tiempos del cristianismo primitivo según Nietzsche, también sería digno de consideración el ya citado artículo de André Mori «Dostoievski», en Journal des Débats, que, como dice Campioni, es una recensión de las traducciones francesas de Humiliés et offensés y Crime et châtiment (cf. G. Campioni, Nietzsche y el espiritu latino, cit., pp. 98-99, nota 162). Según las citas que transcribe Campioni, la «enfermedad nerviosa» estaría muy difundida en Rusia, como estas dos novelas documentan, y su lectura parece que cause el mismo efecto que visitar un manicomio y observar una serie de casos patológicos. 